\title{
Working Memory Tasks in Relation to Phonological Processes of Arab Dyslexics in the State of Kuwait
}

\author{
Mosaad Abo Al-dyiar ${ }^{1} \&$ Ashraf Atta M. S. Salem ${ }^{2}$ \\ ${ }^{1}$ Associate Professor of Psychology, Centre of Children Evaluation and Teaching, State of Kuwait \\ ${ }^{2}$ Kuwait Ministry of Education, State of Kuwait \\ Correspondence: Mosaad Abo Al-dyiar, Centre of Children Evaluation and Teaching, State of Kuwait. E-mail: \\ m.refayi@ccetkuwait.org. Ashraf Atta M. S. Salem, Kuwait Ministry of Education, State of Kuwait. E-mail: \\ sirashrafams@hotmail.com
}

Received: June 24, 2013 Accepted: August 12, 2013 Online Published: August 29, 2013

doi:10.5539/ies.v6n9p107

URL: http://dx.doi.org/10.5539/ies.v6n9p107

\begin{abstract}
The current study investigated the relationship between the working memory tasks and the phonological processes of Arab dyslexics in the primary stage in the State of Kuwait. The researchers used the descriptive research design. The sample of the study consists of 500 pupils (250 males and 250 females), their ages range from $(9.05 \pm 0.49)$ years old. The researchers used the working memory scale, the phonological awareness scale and the dyslexia examination scale. Findings of the study revealed that there is a negative correlation between Rapid Object Naming Test and both Forward Spatial Span Test and Backward Digit Recall Test. Also, there is a negative correlation between Backward Digit Recall Test and Rapid Letter Naming Test. Results also show that there is no correlation between some phonological processes (Syllables \&Sound Deletion Test, Non-Word Repetition Test, and Non-Word Reading Accuracy Test) and the working memory tasks. It is shown that male pupils were slower than their female counterparts in the Rapid Object Naming Test and the Rapid Letter Naming Test.

In addition, male pupils better performed in the Syllables \& Sound Deletion Test, Non-Word Repetition Test, Non-Word Reading Accuracy Test, Forward Spatial Span Test and Backward Spatial Span Test tasks, Forward Digit Recall Test and Backward Digit Recall Test. It is also revealed that there is no significant difference between males and females in the tests of Sentence Repetition Test and Listening Span Test. With regard to nationality, it is revealed that there are significant differences between Kuwaiti and non-Kuwaiti pupils in the Syllables \& Sound Deletion Test, Non-Word Repetition Test, Non-Word Reading Accuracy Test, Sentence Repetition Test and Forward Digit Recall Test in favor of non-Kuwaiti pupils. It is also revealed that there is no significant difference between males and females in the tests of Sentence Repetition Test and Listening Span Test. In addition, it is revealed that the performance of Kuwaiti pupils is slower than that of their non-Kuwaiti counterparts in the tests of Rapid Object Naming, Rapid Letter Naming. Whereas, no significant differences were detected regarding to nationality variable in the Forward Spatial Span Test, Backward Spatial Span Test and Backward Digit Recall Test.
\end{abstract}

Keywords: working memory, phonological processing, dyslexia

\section{Introduction}

Children, adolescents and adults' life is strongly influenced by learning disabilities which are expressed in various ways over an individual lifetime. These ways depend on the interaction between the environmental demands and the individual's strengths and weaknesses (Lerner, 2003; Walcot - Gayda, 2004).

Children with learning disabilities often have lower achievement in relation to their age and intelligence. Those children always have problems in processing auditory or visual information, problems in spelling and writing, difficulties with gross motor ability and fine motor coordination, difficulty with sensory integration involving the tactile, proprioceptive and vestibular systems. (The British Dyslexia Association Handbook, 1995; Johns on, 1997; Mee, 1999, Henry, 2000, Harwell, 2001; Bartholomew, 2002; Lerner, 2003; Woods, 2003, Nangia, 2004; Henry, 2000; Walcot - Gayda, 2004; Jamieson, 2005). 
Dyslexia is an umbrella concept that disguises the truth of a complex matter. It is a clumsy term that creates an automatically negative focus. The concept of dyslexia focuses on small weaknesses of a whole mindset rather than incorporating areas of intellectual differences, many of which are strengths (Juggins, 2001, p.1 as cited in Jamieson, 2003, p. 8).

\subsection{Phonological Awareness}

Phonological awareness, which can be viewed as the ability to manipulate sounds and spoken words, and one of its components, namely the working memory form an essential part of reading and subsequently literacy acquisition (Adams, 1990; Bradley \& Bryant, 1985; De Jong 1998; GatherCole \& Alloway, 2004).

Seymour, Aro \& Erskine (2003) envisage that phonological awareness is a clear predictor of reading competency as it refers to the ability to read words (whether regular or irregular) through splitting words to form syllables and letters and blending letters to form words. This ability helps in developing reading skills as well as facilitating the acquisition of spelling patterns.

Phonological awareness is mistakenly viewed as a single skill that is restricted only to the ability of segmenting speech. Rather it consists of a multitude of cognitive abilities related to the segmental nature of the targeted language (Goswami \& Bryant, 1990)

Gathercole, Alloway, Willis \& Adams (2006) view that phonological awareness and working memory as its verbal components can be assessed by phonological awareness and short-term memory measure. Phonological awareness, as it includes the concept of working memory, is closely related to both working memory, academic success and reading competency. (Gathercole et al, 2006; Gillam \& Van Kleeck, 1996; Midwilsky, 2008). Various attempts in the fields of psychology, neurology and education produced evidence showing that dyslexia is caused mainly as a result of phonological processing deficit that can be improved (optimistically cured) by specific kinds of intensive remediation.

Phonological awareness has been found to be related strongly with dyslexia among Arabic-speakers (Al Mannai \& Everett, 2005; Ashour, 2011; Othman, 2009; Zayed, 2013). It is also evident that intervention is a successful remediation for the reading disorder (Ashour, 2011). In addition, a strong influence was indicated on the ability to read and spell in Arabic speaking dyslexics (Khalil \& Dowah, 2007; Zayed, 2011; Zayed, 2013)

Milwidsky (2008, p.11) views that phonological awareness and working memory are highly correlated in their relationship with the acquisition of reading skills. She concurs that this may be partly returned to the fact that working memory is a component of the phonological awareness. It is argued that acidic success at school is closely linked to the children reading skills. Literacy depends to a large extent on reading skills; therefore it is urgent for researchers as well as educators to identify variables that could predict reading competence as a main indicator of achieving better academic achievement.

In addition, phonological processing can be defined as the use of the sound structure of oral language in processing written and oral information. It is a strong indicator of reading difficulties and of paramount importance for reading acquisition (Bryant, Braddeley, Maclean \& Crossland, 1989; DeJong \& Van der Leij, 1999; Manis, Doi \& Bhadha, 2000; Muter, Hulme, Snowling \& Stevenson, 2004; Parrila, Kirby \& McQuarrie, 2004; Stanovich, 1992; Torgesen, Wagner, Rashotte, Burgess \& Hecht, 1997).

Also, Phonological processing refers to the use of phonological information (i.e., the sounds of one's language) in processing written and oral language (Wagner and Torgesen, 1987, p. 192). Successful performance on tasks such as tapping out the number of sounds in a word, revising the sound order in a word, and putting together sounds presented in isolation to form a word is an evidence of their phonological awareness. In addition, individuals with well-developed phonological awareness represents a reasonable approach to visually representing spoken language whereas individual lacking phonological awareness find it is difficult to make correspondence between symbols and its equivalent sounds.

According to Cockcroft (2002a) and Milwidsky (2008), phonological awareness consists a variety of skills on a broad continuum. It can be defined as an understanding of the structural characteristics of a language, or the awareness of the sound structure of words and the ability to manipulate these sounds. Phonological awareness skills, as working memory, develop - gradually from childhood to maturity as it is manifested in spoken and written language.

Explicit and systematic instruction in phonemic awareness (which includes skills like noticing, identifying and manipulating the sounds of spoken language) and phonics which includes skills like noticing how letters and letter-blends that represent these sounds. Proved to be effective in developing reading fluency, reading comprehension, real word and nonword reading, oral reading and spelling skills among dyslexics (Lyon, 
Shaywitz \& Shaywitz, 2003; Ramus et al. 2003; Shaywitz, 2003; Vellutino, Fletcher, Snowling \& Scanlon, 2004; Blachman, Tungel, Ball, Black \& McGraw, 1999; Brunsdon, Hannan, Nickels \& Clotheart, 2002; Gillon \& Dodd, 1997; Lyon, 1998; Blythe, 2006).

\subsection{Working Memory}

Working memory plays an important part in developing reading skills. Working memory - as a component of phonological awareness - represents a predictor of children's reading ability especially in their early stages of development. It provides a mental workplace for holding information at the same time children are engaged in other relevant activities (Gathercole et al., 2006).

It is worth noting that working memory capacity develops gradually from ages 6 to 19. After that a gradual decline happens to the working memory capacity. Therefore, children's performance on working memory tasks is weaker in the early childhood than it is with older children. In spite of the fact that some structures of memory such as the phonological store are intact in children in the age of three years old. (Siegel, 1994; Gathercole \& Pickering, 2000).

Gather Cole et al. (2006) view that working memory is closely related with severe reading difficulties in the early stages of development specifically in 6- to 11 - years old. That's why Milwidsky $(2008$, p. 12) to say that children having limited working memory capacities struggle with reading and writing tasks as they are unable to hold sufficient information to be able to do the targeted tasks. Working memory can be defined as the ability to hold manipulate information in mind for a short period of time, and can be understood as a flexible mental workspace in which children are able to temporarily store important information in the course of performing complex mental activities (Gathercole \& Alloway, 2004).

Numerous models of working models have been postulated since the mid-1950s as researchers distinguished the concepts of long and short memory. Yet, two main schools prevailed; the first one proposed a domain-specific model and the other a domain-general model. Domain-specific working memory model (shah and Miyake, 1996) proposes that the working memory capacity is supported by two separate pools or domain-specific resources for verbal and visuo-spatial information. Each domain is capable of manipulating and keeping information active implying central executive domain and focusing on the passive short-term storage aspect of memory. Braddeley (2000) proposed another model which is featured by being a domain-general model. According to this model, there is a single domain-general executive resource with two individual domain-specific components, namely visuo-spatial short-term memory and verbal short-term memory.

Braddeley (1996) proposed a renounced memory of working memory. According to this model, there are certain executive functions. The first executive function is the capacity to coordinate performance on two or more separate tasks. The second executive function is switching retrieval strategies. The third executive function is attending selectively to different inputs. The fourth executive function is activating and manipulating information in long-term memory.

To sum-up, there are two distinctive models of working memory; one of Braddeley $(1986,2000)$ which consists of four components, namely the central executive, the phonological loop, the visuo-spatial sketchpad and the episodic buffer. The other model of working memory was proposed by Gathercole and Pickering (2000) working memory-according to this model-includes two separate systems, namely a storage system (short-term memory) that is located in informational domains, and a processing system (working memory) located in the central executive.

\subsection{Review of Literature}

A wide amount of studies were conducted to investigate the relationship between the phonological awareness and working memory of children with dyslexia. Zayed et al., (2013) conducted a study to examine the relationship between phonological awareness, verbal working memory, and the risk in preschool children. A sample of (40) children was selected randomly from 425 preschool children in Egypt and subsequently was divided into two groups: (20) children at risk for dyslexia and (20) normal children. Results of the study reveal that a strong relationship is detected between phonological awareness and working memory. Also, results show that phonological awareness and working memory may have an effect on children's phonological sensitivity and reading skills.

Ramachandra, Hewitt and Brackenburg (2010) conduct a study, to investigate the cognitive abilities needed to succeed at incidental word learning, specifically by examining the role of phonological memory and phonological sensitivity novel word learning by 4-year-old who are developing. The sample of the study consists of forty 4-year-old. Tests used in the study were a test of nonword repetition (to investigate phonological 
memory), rhyming and phoneme alliteration tasks (to investigate phonological sensitivity), and an incidental word learning task (via a computer-based presentation of a cartoon story). Findings revealed that nonword repetition scores did not contribute significantly to incidental word learning. In addition, phonological sensitivity scores were found to be significant predictors of incidental word learning.

Another study was conducted by George, Das and Hayward (2008) to compare the contribution of two different versions of working memory to word reading and reading comprehension in relation to phonological awareness and rapid naming speed. The sample of the study consists of (50) children who were subjected to two measures of working memory, namely an adaptation of the Daneman and Carpenter sentence Span task and sentence Question, tests of phonological awareness, rapid naming speed, word reading and reading comprehension. Findings of the study revealed that Sentence Question accounted for unique variance over and beyond the effects of Daneman and Carpenters' sentence Span task, whereas the latter did not when effects of Sentence Question were partialled out. Also, both phonological awareness and rapid naming were indicated to be unique variance beyond the effects of working memory as a predictor of reading.

Milwidsky (2008) conducted a study to identify the relationship between working memory and the phonological awareness skills in a sample of seventy-nine first grader children (mean ago 86 months) in south Africa. The sample of the study were bilingual pupils representing two language groups, namely first. Language English (EL), an opaque orthography $(n=42)$ and second - language English with first-language one of the nine official African languages of South Africa (EL2), a transparent orthography $(n=37)$. The study aimed specifically at investigating the relationship between phonological awareness (in terms of sound categorization task, a phoneme deletion task, and syllable splitting task) and working memory (in terms of verbal short-term memory task, a visuo-spatial short-term memory task, a verbal working memory task and a visuo-spatial working memory task). She controlled the sample of the study using a measure of non-verbal intelligence.

Results of the study showed that there is a close relationship between working memory and phonological awareness depending on the depth of analysis of phonological awareness, which determines the level of demand made on working memory. Yet, results revealed difference in relationship between the language groups.

\section{Method}

In order to achieve the objectives of the study, the researchers used the comparative correlational descriptive research design. This design was used to investigate the relationships between the phonological processes and working memory tasks of Arab dyslexics and to hold comparisons after adequately describing the study variables.

\subsection{Sampling Procedures and Conditions}

The sample of the study consists of (500) Arab dyslexic pupils in the state of Kuwait (250 males and 250 females) whose mean ages $(9.41+2.24)$ years old.

The sample of the study was selected based on the following criteria:

1) Non-verbal Intelligence test (prepared by Kamal Morsy, 1998) was administered in order to obtain a preliminary estimation of the general mental ability of children whose age ranges from 6 to 14 years old or more. The sample of the study used in this step was 2300 pupils.

2) Pupils whose Intelligence Quotient (IQ) is less than 85 marks were excluded. Those pupils were only 13 pupils according to the Non-verbal intelligence test.

3) Pupils suffering from behavioral problems were excluded. Those pupils represent 24 cases distributed equally by 2 cases suffering from frequent riot and one case suffering from Allgeljh disorder.

4) Pupils who didn't respond to the tests also excluded, five pupils were reluctant to respond to the prescribed tests.

5) Also, pupils suffering from visual or auditory disabilities were excluded. These pupils are (20) pupils (12 visually impaired and 8 hearing impaired).

6) Pupils who are not punctual in their study wee excluded, they were (10) pupils.

7) Pupils suffering from intertwined writing and Math difficulties (25 pupils) were excluded. In addition, pupils suffering from social problem (parents divorce or death of one of them) are accounting (10) pupils.

8) The total number of pupils after excluding the previous cases was 2193 participants.

9) Teachers who are in close contact with pupils were asked to diagnose pupils with dyslexia. 
10) In order to classify dyslexic pupils, the researchers administered Test Reading Dyslexia (Abo Al-diyar, 2013). Frequencies and Percentages of pupils top marks on Reading Dyslexia test were calculated. The total number of dyslexic pupils- based of the test of Reading Dyslexia-were 500 pupils.

11) Equivalence of the sample was assured related to both intelligence and age.

\subsection{Tools of the Study}

The researchers made use of the following tools in order to achieve the study objectives.

\subsubsection{Demographic Variables Format}

This format includes a group of questions and data relating pupils' age, gender, grade, educational directorate and nationality.

\subsubsection{Non-Verbal Intelligence Test (Kamal Morsy, 1998)}

This test is used to obtain a preliminary estimation of the general mental ability of children whose age ranges from 6 to 14 years old and above. Non-verbal Intelligence Test measures the children's ability to think through realizing relationships between groups of symbols, pictures of geometric shapes, characters, animals, plants or instruments. This test has got two advantages; the first is that it is free of linguistic stimuli as the test items are symbols and pictures. The children respond to the test items through making a sign. Therefore, tests of this kind can be administered without using speech and language. Thus, it is preferred to use these kinds of tests with children suffering from speech and language difficulties to measure their intellectual ability. The second advantage of this test is that it is free of formal school factor. Being able to respond successfully to the test items doesn't depend on the participants' ability to read and write. Furthermore, the test requires participants to have academic experiences directly related to the test. Therefore, this kind of test is appropriate and reliable so as to produce a preliminary estimation of the thinking ability of illiterate and low achievers to provide this with the necessary vocational and educational guidance according to their mental ability.

\subsubsection{Reliability and VALIDity of Non-Verbal Intelligence Test}

Reliability and validity of the test were calculated using various statistical methods. Reliability Alpha Cronach's coefficients were $(0.88)$ and $(0.89)$. Test validity was measured using concurrent validity through administering both the Non-verbal intelligence test and Kuwait Stanford-Binet scale. Validity coefficient of intelligence standard deviation of the two scales was (0.39) which is significant on the level of (0.01) referring to the positive concurrency between intelligence percentages in the two scales.

\subsubsection{Phonological Processes Test Battery}

This test battery was developed by Taiba et al. (2010) in order to provide a standardized diagnostic instrument derived from the Arab environment to measure phonological tasks. This battery is suitable for children in the primary schools (grades two to five primary school) whose age ranges from (7) to (11) years old.

This battery consists of five sub-tests which aim at investigating the children's knowledge of the nature of speech processing at the level of words, syllables, and phonemes. The following are the sub-tests of the Phonological Processes Test Battery:

\section{Rapid Object Naming Test}

This test consists of a group of shapes divided into two models (A) and (B). These models are shown to the participants. Then participants are asked to name these objects as fast as possible. Time and number of errors are calculated for each model.

\section{Rapid Letter Naming Test}

This test consists of a group of letters divided into two models (A) and (B) shown to the participants. Then participants are asked to name these letters as fast as possible. Time and number of errors are calculated for each model.

\section{Syllables \& Sound Deletion Test}

This test consists of (20) words which the participant listens to them carefully through the CD player. Participants then delete a syllable from the word and proceed to deleting only one sound of the word.

\section{Non-word Repetition Test}

This test consists of (20) unreal words (pseudo words). Participants listen to these words through the CD player carefully then repeat these words. The total score of the test is the outcome of summing the pseudo-words participants repeat correctly. 


\section{Non-Word Reading Accuracy Test.}

This test consists of (25) unreal (pseudo or meaningless) words which participants look at then read correctly.

\subsubsection{Standardized Test of Working Memory for Children (Abo Al-dyiar et al., 2013)}

This test measures the efficiency of various types of working memory. The working memory plays a vital role in children learning of basic reading skills especially reading comprehension skills. This battery of tests measures the working memory tasks of children whose age ranges from 7 to 11 years old.

The standardized Test of Working Memory for Children is characterized by being clear, attractive for children, it can be taken individually, it also can be used in various fields. The administration of the test only needs needs only simple training for the examiners. This battery includes the following sub-tests:

\section{Forward Spatial Span Test}

This test consists of a group of circles. The examiner should refer to these circles according to certain sequence. As the examiner finishes, a participant should refer to these circles with the same order as that of the examiner. The examiner writes down the results in the answer sheet. One point is given when the participant follows the same order as that of the examiner. Zero is given when the participant doesn't follow the same order as that of the examiner. A participant total score is the sum of right answers (18 marks).

\section{Backward Spatial Span Test}

This test consists of a group of $(\mathrm{g})$ circles. The examiner should refer to these circles according to certain sequence. As the examiner finishes, a participant should refer to these circles in a reverse sequence of that used by the examiner. Then the examiner writes down the results in the answer sheet. One point is given for right answer, while (0) is given when the participant fails to answer correctly. The total score of the right answers is (18) points.

\section{Sentence Repetition Test}

This test consists of (15) sentences participants listen to these sentences carefully, one sentence each time. Then a participant tries to remember the sentence exactly and in the same sequence the examiner read as fast as possible. The participant is given one mark for each right word mentioned in the same sequence as that of the examiner as fast as possible. The examiner writes the sentence which a participant mentions exactly. The examiner then goes on to read the next sentence allowing the participant enough time to answer. The total score given for each sentence represents the number of right words mentioned by the participant in the right sequence. Words similar to the actual words mentioned by the examiner are considered to be wrong. It is worth noting that the conjunction "and" ("wa" in Arabic) is considered a separate word. If a participant mentions right words in the wrong sequence, it is considered wrong answer. The examiner writes down time a participant spent in responding to each sentence. Total score of the test (197) points which represents the sum of right words the participant mentioned in the right sequence.

\section{Forward Digit Recall Test}

This test consists of a group of digits ordered in certain sequence one after another. A participant listen to these digits, then the examiner asked the children to mention these digits in the same sequence as that of the examiner. One point is given for the right answer while zero is given for the wrong one. Total score of the test is (21) points.

\section{Backward Digit Recall Test}

This test consists of a group of digits ordered in certain sequence one after another. A participant listen to these digits, then he/she is asked to mention these digits in reversed sequence to that of the examiner. One point is given for the right answer while zero is given for the wrong one. The total score of test is (21) points.

\section{Listening Span Test}

This test consists of a group of sentences, a participant listen carefully to each sentence and think of it. A participant should decide whether the sentence is right and meaningful or wrong and meaningless. Then participants should recall the last word in each sentence in the right order. Participants shouldn't start recalling until the examiner shakes his head. One point is given to the right answer and zero is given to the wrong one. Total score (6) is a sum of right answers. 


\subsubsection{Dyslexia Test}

This test is prepared by Abo Al-dyiar (2013), it consists of (10) items. The test follow Likert scale; (5) represents (usually), (4) represents (often), (3) represents (sometimes), (2) represents (seldom), and (1) represents (Not applicable). The total score of the test is (50) marks.

\subsection{Psychometric Properties of Study Tools}

In order to ensure the psychometric efficiency of the study tools, the researchers piloted these tools $(\mathrm{N}=100)$ on primary stage pupils $($ Male $=50$, female $=50$ ). Male participants mean age equals $9.21+0.76$ while female participants mean age equals $9.10+0.61$. This pilot study sample is similar to the sample of the study. Reliability and validity of working memory, phonological awareness and dyslexia tests was measured as follows:

\subsubsection{Reliability of Study Tools}

Reliability was calculated through three different methods:

\subsubsection{Alpha Cronbach Method}

This method which depends on the correlation coefficient of scale items as well as the correlation coefficients between each item and the total score of the test.

\subsubsection{Test-Retest Method}

According to this method, the test was administered twice with 20 days' time interval between the two test sessions in order to eliminate the effect or memorizing. Test-retest method is used to measure the reliability coefficient which is called stability coefficient which is influenced by error caused by discrepancy in evaluation (Abu Hatab, Othman and Sadek, 1999).

\subsubsection{Split-Half Method (Guttman Method)}

According to this method, the researcher calculate correlation coefficients between single numbered items with double numbered items in the test based on the test type whether it can be divided into two parts or not (Ghoneim, and Nasr, 1998).

Table 1 shows the reliability coefficients of males and females in the tests used in the study.

Table 1. Reliability coefficient of phonological awareness, working memory and dyslexia tests

\begin{tabular}{lcccccccc}
\hline Reliability Coefficients Tests & $\begin{array}{c}\text { No. of } \\
\text { Items }\end{array}$ & & Means(n=50) & & \multicolumn{3}{c}{ Females $(\mathbf{n = 5 0})$} \\
& & Alpha & Split-halt & $\begin{array}{c}\text { Test } \\
\text { retest }\end{array}$ & Alpha & Split-halt & $\begin{array}{c}\text { Test } \\
\text { retest }\end{array}$ \\
\hline Rapid Object Naming Test & $\mathbf{7 2}$ & $\mathbf{0 . 8 4}$ & $\mathbf{0 . 8 9}$ & $\mathbf{0 . 9 4}$ & $\mathbf{0 . 8 6}$ & $\mathbf{0 . 7 6}$ & $\mathbf{0 . 8 7}$ \\
Test Rapid Letter Naming & $\mathbf{7 2}$ & $\mathbf{0 . 7 6}$ & $\mathbf{0 . 8 7}$ & $\mathbf{0 . 7 6}$ & $\mathbf{0 . 8 0}$ & $\mathbf{0 . 7 4}$ & $\mathbf{0 . 7 9}$ \\
Test Syllables \&Sound & 20 & $\mathbf{0 . 7 2}$ & $\mathbf{0 . 7 5}$ & $\mathbf{0 . 7 2}$ & $\mathbf{0 . 7 4}$ & $\mathbf{0 . 6 9}$ & $\mathbf{0 . 7 6}$ \\
Deletion & & & & & & & \\
Non-Word Repetition Test & 20 & $\mathbf{0 . 8 3}$ & $\mathbf{0 . 6 9}$ & $\mathbf{0 . 7 8}$ & $\mathbf{0 . 7 6}$ & $\mathbf{0 . 7 8}$ & $\mathbf{0 . 7 9}$ \\
Non-Word Reading Accuracy & 25 & $\mathbf{0 . 8 0}$ & $\mathbf{0 . 8 9}$ & $\mathbf{0 . 8 9}$ & $\mathbf{0 . 7 7}$ & $\mathbf{0 . 7 8}$ & $\mathbf{0 . 8 7}$ \\
Test & & & & & & & \\
Forward Spatial Span Test & 15 & $\mathbf{0 . 9 1}$ & $\mathbf{0 . 9 0}$ & $\mathbf{0 . 8 6}$ & $\mathbf{0 . 7 7}$ & $\mathbf{0 . 7 8}$ & $\mathbf{0 . 8 7}$ \\
Backward Spatial Span Test & 21 & $\mathbf{0 . 8 4}$ & $\mathbf{0 . 7 8}$ & $\mathbf{0 . 7 3}$ & $\mathbf{0 . 8 0}$ & $\mathbf{0 . 7 8}$ & $\mathbf{0 . 7 8}$ \\
Sentence Repetition Test & 18 & $\mathbf{0 . 7 9}$ & $\mathbf{0 . 7 7}$ & $\mathbf{0 . 7 8}$ & $\mathbf{0 . 7 4}$ & $\mathbf{0 . 8 9}$ & $\mathbf{0 . 8 7}$ \\
Forward Digit Recall Test & 21 & $\mathbf{0 . 7 2}$ & $\mathbf{0 . 7 2}$ & $\mathbf{0 . 7 5}$ & $\mathbf{0 . 8 2}$ & $\mathbf{0 . 7 3}$ & $\mathbf{0 . 8 4}$ \\
Backward Digit Recall Test & 18 & $\mathbf{0 . 9 0}$ & $\mathbf{0 . 9 2}$ & $\mathbf{0 . 8 7}$ & $\mathbf{0 . 9 1}$ & $\mathbf{0 . 7 9}$ & $\mathbf{0 . 7 8}$ \\
Listening Span Test & 6 & $\mathbf{0 . 7 9}$ & $\mathbf{0 . 7 4}$ & $\mathbf{0 . 8 1}$ & $\mathbf{0 . 8 2}$ & $\mathbf{0 . 7 8}$ & $\mathbf{0 . 8 0}$ \\
Dyslexia Test & 10 & $\mathbf{0 . 8 2}$ & $\mathbf{0 . 7 2}$ & $\mathbf{0 . 7 4}$ & $\mathbf{0 . 7 5}$ & $\mathbf{0 . 8 3}$ & $\mathbf{0 . 8 8}$ \\
\hline
\end{tabular}

Close inspection of table 1 reveals high reliability coefficients for both male and female participants in the battery of tests of phonological processes, working memory and dyslexia.

\subsubsection{Validity of Study Tools}

Validity of the study tools was calculated using criterion-related validity. Correlation coefficient of pilot study sample (100 participants) in Diagnostic Reading Comprehension Test (Abo-Adyiar et al., 2010) and the current 
test used in this study was calculated (0.61). With regard to criterion-referenced validity of the working memory test and the working memory test (Soliman, 2006), the correlation coefficient was $(0.55-0.67)$.

Regarding phonological processes, correlation coefficients between phonological processes test used in the study and the phonological awareness and recognizing digits and letter test (Abdullah, 2006). The correlation coefficient was between (0.52) and (0.65).

\subsection{Administration Procedures}

In order for the researchers to test the study hypotheses, certain procedures were followed. These procedures include preparing the tools of the study and controlling variables. A pilot study was conducted on a similar sample to that of the study itself. In order to ensure the reliability and validity of the study tools. The following steps were followed to conduct the current study:

1) A consent was taken from Kuwait Ministry of Education to administer tools of the study.

2) The sample of the study was selected randomly.

3) Variables control and ensuring equivalence between males and females using Non-verbal Intelligence Test. Using Non-verbal Intelligence Test was aimed to assess participants' intelligence level and ensure sample equivalence. Participants whose scores in the Non-verbal intelligence test less than (85) points were excluded. Then, participants score in achievement test in Arabic in the first term 20/2/2013 were calculated. After that, the sample of the study was selected. Finally, tests of working memory and phonological processes were administered.

\subsection{Statistical Treatment}

Several statistical methods were used to answer questions of the study and to verify the study variables. The researchers used the statistical package of social science (SPSS) in order to work out the following:

1. Descriptive Statistics which include:

* Means and standard deviations

* Alpha Cronbach's Coefficient

* Pearson Correlation Coefficient.

2. Inferential Statistics which include:

* T-test value to assess significance of mean difference of scores.

\section{Results}

3.1 Pearson Correlation Coefficient Significance Working Memory Tasks and Phonological Processes

Table 2. Pearson correlation coefficient significance $(\mathrm{N}=500)$

\begin{tabular}{llllll}
\hline Correlations & $\begin{array}{l}\text { Rapid Object } \\
\text { Naming }\end{array}$ & $\begin{array}{l}\text { Rapid } \\
\text { Letter } \\
\text { Naming }\end{array}$ & $\begin{array}{l}\text { Syllables } \\
\text { \&Sound } \\
\text { Deletion }\end{array}$ & $\begin{array}{l}\text { Non-Word } \\
\text { Repetition }\end{array}$ & $\begin{array}{l}\text { Non-Word } \\
\text { Reading } \\
\text { Accuracy }\end{array}$ \\
\hline Forward Spatial Span & $-0.107^{*}$ & 0.29 & 0.001 & 0.016 & 0.016 \\
Backward Spatial Span & 0.082 & 0.065 & -0.071 & -0.004 & 0.014 \\
Sentence Repetition & 0.016 & 0.056 & 0.021 & 0.038 & -0.007 \\
Forward Digit Recall & -0.078 & 0.013 & -0.013 & 0.000 & -0.044 \\
Backward Digit Recall & $0.095^{*}$ & $-0.097^{*}$ & -0.059 & 0.002 & 0.000 \\
Listening Span & 0.023 & 0.020 & 0.033 & 0.022 & 0.059 \\
\hline
\end{tabular}

* Correlation is significant at the 0.05 level (2-tailed).

Table 2 shows Pearson correlation coefficients between working memory tasks and phonological processes of the study participants $(\mathrm{N}=300)$. Close inspection of table 2 reveals that there is a negative relationship between Forward Spatial Span Test score and Rapid Object Naming Test score. This means that a participant who got longer time for naming object is not well in forward spatial span test.

In addition, results revealed a negative relationship between Backward Digit Recall Test and Rapid Letter Naming Test. This refers that participants who take longer time in naming letters and shapes perform weakly in backward digit recall test. 


\subsection{Significance of Differences between Males and Females in Working Memory Tasks and Phonological Processes Tests}

The researchers used T-test in order to test the significance of mean differences of scores of males and females.

Table 3. Mean scores, standard deviations and t-test values of males and females in tests of working memory and phonological processes

\begin{tabular}{lccccc}
\hline \multicolumn{1}{c}{ Tests } & \multicolumn{2}{c}{ Means $(\mathbf{n}=\mathbf{2 5 0})$} & \multicolumn{2}{c}{ Females $(\mathbf{n}=\mathbf{2 5 0})$} & \multirow{2}{*}{ T } \\
& Mean & Std.Devation & Mean & Std.Devation & \\
\hline Rapid Object Naming Test & 39.60 & 10.45 & 36.01 & 8.82 & $2.75^{*}$ \\
Test Rapid Letter Naming & 30.28 & 12.69 & 26.26 & 10.76 & $3.82^{* *}$ \\
Test Syllables \&Sound Deletion & 10.53 & 4.48 & 9.96 & 2.26 & 1.47 \\
Non-Word Repetition Test & 11.87 & 3.44 & 9.66 & 3.37 & $7.19^{* *}$ \\
Non-Word Reading Accuracy & 16.45 & 7.51 & 14.53 & 8.06 & $2.73^{*}$ \\
Test & & & & & \\
Forward Spatial Span Test & 9.48 & 2.53 & 8.71 & 2.48 & $3.36^{* *}$ \\
Backward Spatial Span Test & 6.73 & 3.08 & 5.67 & 2.74 & $4.05^{* *}$ \\
Sentence Repetition Test & 41.01 & 14.11 & 38.24 & 14.47 & $2.15^{*}$ \\
Forward Digit Recall Test & 9.68 & 2.19 & 9.72 & 2.25 & 0.215 \\
Backward Digit Recall Test & 4.25 & 1.63 & 3.86 & 1.38 & $2.88^{* *}$ \\
Listening Span Test & 3.59 & 2.42 & 3.33 & 2.31 & 1.18 \\
\hline
\end{tabular}

** Significant at the 0.01 level (2-tailed).

* Significant at the 0.05 level (2-tailed).

Close inspection of table 3 reveals that there is a significant difference in the mean scores of males and females in the tests of Rapid Letter Naming and Rapid Object Naming.

Males outperformed females in the tests of Non-word Repetition, Non-word Reading Accuracy, Forward Spatial Span, Backward Spatial Span, Sentence Repetition and Backward Digit Recall while no significant differences were detected between the mean scores of males and females in other tests.

\subsection{Differences between Kuwaitis and Non-Kuwaitis in Working Memory Tasks and Phonological Processes}

Table 4. Mean scores, standard deviations and t-test values of Kuwaitis and Non-Kuwaitis of working memory tasks and phonological processes

\begin{tabular}{lccccc}
\hline \multicolumn{1}{c}{ Tests } & \multicolumn{2}{c}{ Kuwaiti (n=459) } & \multicolumn{2}{c}{ Non-Kuwaiti (n=41) } & \multirow{2}{*}{ T } \\
& mean & Std.Devation & mean & Std.Devation & \\
\hline Rapid Object Naming Test & 39.23 & 10.17 & 32.85 & 7.49 & $3.92^{* *}$ \\
Test Rapid Letter Naming & 28.41 & 12.10 & 23.83 & 6.65 & $2.39^{*}$ \\
Test Syllables \&Sound Deletion & 10.01 & 4.37 & 12.46 & 3.58 & $3.48^{* *}$ \\
Non-Word Repetition Test & 10.53 & 3.57 & 11.80 & 3.47 & $2.19^{*}$ \\
Non-Word Reading Accuracy Test & 15.11 & 7.96 & 18.27 & 6.17 & $2.47^{*}$ \\
Forward Spatial Span Test & 9.09 & 2.55 & 8.65 & 2.31 & 1.04 \\
Backward Spatial Span Test & 6.15 & 2.94 & 6.07 & 2.87 & 0.161 \\
Sentence Repetition Test & 39.07 & 14.20 & 43.83 & 15.59 & $2.04^{*}$ \\
Forward Digit Recall Test & 9.64 & 2.21 & 10.49 & 2.20 & $2.35^{*}$ \\
Backward Digit Recall Test & 4.03 & 1.53 & 4.07 & 1.31 & 0.182 \\
Listening Span Test & 3.39 & 2.33 & 4.12 & 2.63 & 1.90 \\
\hline
\end{tabular}

** Significant at the 0.01 level (2-tailed).

* Significant at the 0.05 level (2-tailed).

Close examination of table 4 reveals that there are significant differences of mean scores between Kuwaitis and Non-Kuwaitis in favor of non-Kuwaitis in the tests of Rapid Object Naming, Rapid Letter Naming, Syllables \& Sound Deletion, Non-word Repetition, Non-word Reading Accuracy, sentence Repetition, and Forward Digit Recall. Whereas, no significant differences were detected between Kuwaitis and Non-Kuwaitis in the other tests. 


\section{Discussion}

There is a negative correlation between Rapid Object Naming Test and both Forward Spatial Span Test and Backward Digit Recall Test. Also, there is a negative correlation between Backward Digit Recall Test and Rapid Letter Naming Test. This finding is in contrast with that of a study conducted by Das and Hayward (2008) which indicated the influence of working memory on word reading and reading comprehension in relation to phonological awareness and rapid naming speed.

Results of the current study show that there is no correlation between some phonological processes (Syllables \&Sound Deletion Test, Non-Word Repetition Test, and Non-Word Reading Accuracy Test) and the working memory tasks. This also contradicts with the study conducted by Zayed et al., (2013) which indicated the presence of a strong relationship between phonological awareness and working memory that may have an effect on children's phonological sensitivity and reading skills. In addition, the current study results contradict with results reached in a study of Milwidsky (2008) that revealed a close relationship between working memory and phonological awareness.

Results drawn in the study conducted by Zayed et al., (2013) are logically coincided with the current study as both of these studies dealt with Arab children, which means that the sample of the two studies are similar. Yet, the sample of the current study is much larger than that of Zayed et al., (2013) study.

Findings of the current study consolidated the results of almost all the studies as it showed the correlation between working memory tasks and the phonological processes.

\section{References}

Abdullah, A. (2006). Mental and Cognitive development of Kindergarten children with pre-academic skills shortage as a predictor of learning Difficulties. Children Disabilities conference, Faculty of Education. Kuwait University. In the period, $20^{\text {th }}-22^{\text {nd }}$ March, 2006.

Abo Al-dyiar, M., Al Behairi, G., Mahfoudhi, A., \& Hatab, S. (2010). Diagnostic Tests in Arabic Language: Test Guide. Kuwait: Centre of Children Evaluation and Teaching.

Abo Al-dyiar, M., Evarett, J., Al Behairi, G., Taiba, N., \& Mahfoudhi, A. (2013). Standardized Test of working Memory for Children. Kuwait: Centre of Children Evaluation and Teaching.

Abo Hatab, F., Othman, S., \& Sadek, A. (1999). Psychological Evaluation. Cairo: Anglo Egyptian Publishing Co.

Adams, M. J. (1990). Beginning to Read: Thinking and Learning about Print. Cambridge, MA: MIT Press.

Al Mannai, H., \& Everatt, J. (2005). Phonological processing skills as predictors of literacy amongst Arabic speaking Bahraini school children. Dyslexia, 11, 269-291. http://dx.doi.org/10.1002/dys.303

Ashour, A. (2011). The phonological awareness and its role in diagnosing and treating the children with dyslexia. Arabian Journal of Learning Disabilities, 1(1), 243-257.

Baddeley, A. D. (2000). The episodic buffer: A new component of working memory. Trends in Cognitive Science, 4, 417-423.

Bartholomew, I. (2002). Demystifying Dyslexia. The Rotarian Dyslexia Awareness and Resource Centre. Retrieved from www.dyslexiacenter.org

Blachman, B. A., Tingle, D. M., Ball, E. W., Black, R., \& McGraw, C. K. (1999). Developing phonological awareness and word recognition skills: A two-year intervention with low-income, inner-city children. Reading and Writing: An Interdisciplinary Journal, 11, 239-273.

Blythe, J. M. (2006). Computer-based phonological training for primary students with mild to moderate dyslexia - a pilot study. Australian Journal of Education and Developmental psychology, 6, 39-49.

Braddeley, A. D. (1986). Working memory. London: Oxford University Press.

Bradley, L., \& Bryant, P. E. (1985). Rhyme and reason in reading and spelling. Michigan: University of Michigan Press.

Brunsdon, R. K., Hannan, T, J., Nickels, L., \& Coltheart, M. (2002). Successful treatment of sub lexical reading deficits in a child with dyslexia of the mixed type. Neuropsychological Rehabilitation, 12, 199-229.

Bryant, P. E., Bradley, L., Maclean, M., \& Crossland, J. (1989). Nursery rhymes, Phonological skills and reading. Journal of Child Language, 16, 407-428. 
Cockcroft, K. A. S. (2002a). Ready for reading: concurrent and longitudinal predictors of reading in English. Unpublished Doctor of Philosophy thesis, University of the Witwatersrand, South Africa.

De Jong, P. F. (1998). Working memory deficits of reading disabled children. Journal of Experimental Child Psychology, 76, 75-96.

De Jong, P. F. \& Van der Leij, A. (1999). Specific contributions of phonological abilities to early reading acquisition: Results from a Dutch Latent variable longitudinal study. Journal of Educational Psychology, 91, 450-476.

Gathercole, S. E., \& Alloway, T. P. (2004). Working memory and classroom learning. Dyslexia Review, 15, 4-9.

Gathercole, S. E., \& Alloway, T. P. (2006). Practitioner Review: Short-term and working memory impairments in neurodevelopmental disorders: diagnosis and remedial support. Journal of Child Psychology and Psychiatry, 47(1), 4-15.

Gathercole, S. E., \& Pickering, S. J. (2000). Assessment of working memory in six- and seven-year old children, Journal of Educational Psychology, 92, 377-390.

Gathercole, S. E., Alloway, T. P., Willis, C., \& Adams, A. M. (2006). Working memory in children with disabilities. Journal of Experimental Child Psychology, 9, 265-281.

Georgiou, G. K., Das, J. P., \& Hayward, D. V. (2008). Comparing the contribution of two tests of working memory to reading in relation to phonological awareness and rapid naming speed. Journal of Research of Reading, 31(3), 302-318. http://onlinelibrary.wiley.com/doi/10.1111/j.1467-9817.2008.00373.x/pdf

Ghonaim, A., \& Nasr, M. (2000). Statistical Analysis Using SPSS. Cairo: Qebaa Publishing House.

Gillam, R. B., \& van Kleeck, A. (1996). Phonological awareness training and short-term working memory: Clinical implications. Topics in Language Disorders, 17(1), 72-81.

Gillon, G., \& Dodd, B. (1997). Enhancing the phonological processing skills of children with specific reading disability. European Journal of Disorders of Communication, 32, 67-90.

Goswami, U., \& Bryant P. (1990). Phonological skills and learning to read. Hillsdale, NJ: Lawrence Erlbaum Associates.

Harwell, J. M. (2001). The Complete Learning Disabilities Handbook (2nd ed). San Francisco: Jossey-Bass.

Henry, M. K. (2000). The Orton-Gillingham Approach to Teaching Reading, from The International Dyslexia Association. Retrieved October 10, 2004, from http://www-gohonics.com/index.htm

Jamieson, N. Y. (2005). The contribution of the Montessori Approach to Multisensory Approaches to Early Learning Disabilities. Unpublished Masters of Education. University of the Witwatersrand. Johannesburg.

Juggins, M. (2001). Dyslexics, Drowning in the Mainstream, from the Dyslexia Online Journal on the World. Retrieved from http://www.dyslexia-adults.com/journal.html Retrieved 10 October 2004

Khalil, M., \& Dowah, A. (2007). Working memory disorders as a predictor of dyslexia level of primary school students. Egyptian Journal of psychological studies, 49(15), 247-321.

Lerner, J. W. (2003). Learning Disabilities: Theories. Diagnosis and Teaching Strategies (9th ed.). New York: Houghton Mifflin Company

Lyon, G. R., Shaywitz, S. E., \& Shaywitz., B. A. (2003). Defining Dyslexia, Co morbidity, Teachers' Knowledge of Language and Reading: A Definition of Dyslexia. Annals of Dyslexia, 53, 1-14.

Lyon, G.R. (1998). Why reading is not a natural process. Educational Leadership, 55, 14-18.

Manis, F. R., Doi, L. M., \& Bhadha, B. (2000). Naming speed, phonological awareness, and orthographic knowledge in second graders. Journal of Learning Disabilities, 33, 325-333.

Mclean, J. F., \& Hitch, G. J. (1999). Working memory Impairments in children with Specific Arithmetic Learning Difficulties. Journal of Experimental Child psychology, 74, 240-260.

Mee, M.Y. (1999). Help for Dyslexics. The English Teacher: 28.

Milwidsky, C. (2008). Working Memory and Phonological Awareness. Unpublished Master of Psychology thesis. Faculty of Humanities, University of the Witwatersrand, Johannesburg.

Morsy, K. I. (1998). Non-verbal Intelligence Test. Kuwait: Ministry of Education, Social and Psychological Services Department. 
Muter, V., Hulme, C., Snowling, M., \& Stevenson, J. (2004). Phonemes, rimes vocabulary, and grammatical skills as foundation of early reading development: Evidence from a longitudinal study. Developmental Psychology, 40, 665-681.

Nangia, B. (2004). A Study for the Development and Validation of Remedial Programmes for Promoting Education of Dyslexic Children in Mainstream Schools. Retrieved 10 October 2004 from http://jiml.nic.in/index.htm

Othman, R. (2009). Effectiveness of training program to improve phonological awareness for dyslexic kindergarten children . Unpublishe master's thesis. Kafrelsheikh, Egypt.

Parrila, R., Kirby, J. R., \& McQuarrie, L. (2004). Articulation rate, naming speed, verbal short-term memory, and phonological awareness: Longitudinal predictors of early reading development. Scientific Studies of Reading, 8, 3-26.

Ramachandra, V., Hewitt, L., \& Brackenburg, T. (2010). The relationship between phonological memory, phonological sensitivity, and Incidental word Learning. Journal of Psycholinguist Research. Retrieved from www.bgsu.edu/downloads/chhs/file87889. http://dx.doi.org/doi.10.1007/s10936-010-a157-8

Ramus, F., Rosen, S., Dakin, S. C., Day, B. L., Castellote, J. M., White, S., \& Frith, U. (2003). Theories of developmental dyslexia: Insights from a multiple case study of dyslexic adults. Brain, 126, 841-865.

Seymour, P. H. K., Aro, M., \& Erskine, J. M. (2003). Foundation literacy acquisition in European orthographies. British Journal of Psychology, 94, 143-174.

Shah, P., \& Miyake, A. (1996). The separability of working memory resources for spatial thinking and language processing: An individual differences approach. Journal of Experimental Psychology: General, 125, 4-27.

Shaywitz, S. E. (2003). Overcoming Dyslexia: A new and complete science-based program for reading problems at any level. Alfred A. Knopf: New York.

Siegel, L. S. (1994). Working memory and reading: A life-span perspective. International Journal of Behavioral Development, 17, 109-124.

Soliman, M. (2006). The effect of Phonological Awareness Training on Remediation of some reading difficulties. A paper presented to the sixth scientific conference of the Egyptian Association for Reading literacy "It is every children right to be a distinguished reader" in the period 12-13 July, 2006, Cairo. pp. 123-179.

Stanovich, K. E. (1992). Speculations on the causes and consequences of individual differences in early reading acquisition. In P. B. Gough, L. C. Ehri, \& R. Treiman (Eds.), Reading acquisition. Hillsdale, NJ: Erlbaum Associates.

Taiba, N., Al Behairi, G., Abo Al-dyiar, M., Mahfoudhi, A., Everat, J., \& Heinz, Charles. (2010). Standardized Test of Phonological Processes for Children. Kuwait. Centre of Children Evaluation and Teaching.

Torgesen, J. K., Wagner, R. K., Rashotte, C. A., Burgess, S., \& Hecht, S. (1997). Contributions of phonological awareness and rapid automatized naming ability to growth of word-reading skills in second- to fifth-grade children. Scientific Studies of Reading, 1, 161-185.

Vellutino, F. R., Fletcher, J. M., Snowling, M. J., \& Scanlon, D. M. (2004). Specific reading disability (dyslexia): What have we learned in the past four decades? Journal of Child Psychology and Psychiatry, 45, 2-40.

Wagner, R. K., \& Torgesen, J. K. (1987). The Nature of phonological processing and its casual Role in the Acquisition of Reading skills. Psychological Bulletin, 101(2), 192-212.

Walcot-Gayda, E. (2004). Understanding Learning Disabilities. Education Canada, 44(1).

Woods, C. (2003). Phonemic Awareness: A Crucial Bridge to Reading. Montessori Life, 15(2), 37.

Zayed, A. M., Roehring, A. D., Lloyd, M. C., \& Gilgril, N. (2013). Phonological Awareness and working memory in Arabic-speaking Egyptian preschool Children at Risk for Dyslexia. International Journal of Psychological studies, 5(1), 139-149. http://dx.doi.org/10.5539/Ups.v5n1p139

\section{Copyrights}

Copyright for this article is retained by the author(s), with first publication rights granted to the journal.

This is an open-access article distributed under the terms and conditions of the Creative Commons Attribution license (http://creativecommons.org/licenses/by/3.0/). 